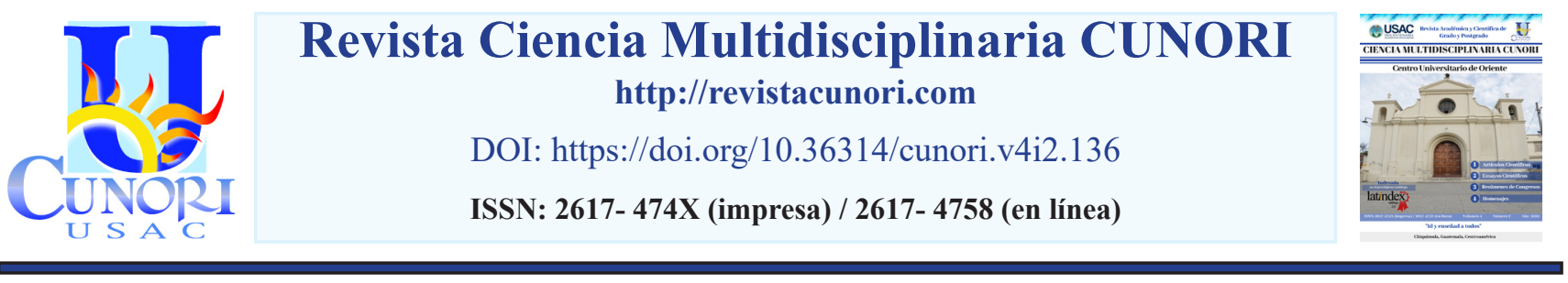

Referencia del artículo

Castillo-López, N. C. (2020). El fenómeno del Coronavirus y el Biodesarrollo: sus consecuencias y oportunidades. Revista Ciencia Multidisciplinaria Cunori, 4(2), 125-132. https://doi.org/10.36314/cunori.v4i2.136

\title{
El fenómeno del Coronavirus y el Biodesarrollo: sus consecuencias y oportunidades
}

\section{The Coronavirus phenomenon and Biodevelopment: its consequences and opportunities}

\author{
Nancy Carolina Castillo López \\ Doctorado en Investigación en Educación \\ Centro Universitario de Oriente, Universidad de San Carlos de Guatemala \\ https://orcid.org/0000-0003-0079-1466 \\ Recibido: 09 de mayo de 2020 / Revisado: 18 de mayo de 2020 / Aceptado: 05 de junio de 2020 \\ Disponible en internet el 30 de octubre de 2020 \\ *Autor para correspondencia. \\ Correo electrónico: ncastillodelinares@yahoo.com
}

\section{Resumen}

$\mathrm{L}$

a búsqueda de un desarrollo que promocione la vida debería de ser la meta de cada uno de los Estados modernos. Actualmente, Llos sistemas económicos y políticas de desarrollo apuntan únicamente a un crecimiento desmedido de la economía que no prioriza la vida, en toda la extensión de la palabra. Una crisis originada por la proliferación del Covid-19, un virus altamente infeccioso, tiene al mundo paralizado cuestionándose sobre las estrategias necesarias para proteger la vida, sin embargo, es necesario detenerse a pensar si el ritmo vertiginoso de relaciones que sosteníamos hasta la fecha exalta la vida o la destruye. Las lecciones que obtengamos de este fenómeno marcarán la diferencia.

Palabras clave: coronavirus, biodesarrollo, consecuencias, oportunidades

Abstract

$\mathrm{T}$

The search for a development that promotes life should be the goal of each of the modern States. Currently, economic systems

and development policies, only point to an excessive growth of the economy that does not prioritize life, in the full extent of the word. A crisis caused by the proliferation of Covid-19, a highly infectious virus, has the world paralyzed wondering about the necessary strategies to protect life, however, it is necessary to stop to think, if the dizzying pace of relationships that we have sustained today, exalts life or destroy it. The lessons we learn from this phenomenon will make a difference.

Keywords: coronavirus, biodevelopment, consequences, opportunities 


\section{Introducción}

"Vivimos en un mundo cambiante, con un muy elevado ritmo que adopta velocidades crecientes, un mundo alta y crecientemente interdependiente y por lo tanto no lineal" (Maldonado, 2001, p. 23-24 ), esto se hace más evidente a la luz de estos tiempos, en donde el statu quo se ha modificado y la vida nos ha cambiado completamente. Por más que soñemos con que las cosas volverán a la "normalidad" entendida ésta como, la forma de vida a la que estábamos acostumbrados, las cosas ya nunca volverán a ser iguales, porque la vida ya cambió.

De un día a otro el mundo nos sorprende con una enfermedad que ha sido capaz de transformar la vida de la mayoría de habitantes en todo el planeta, el Covid-19 (coronavirus) ha llegado para trastocar todas las fibras de los seres humanos empezando por su salud física y mental y siguiendo por su economía, política y gobiernos: adquiriendo estos últimos un papel mucho más activo y protagónico. Los retos que plantea esta pandemia, tanto personales, familiares como para los Estados, son inmensos y las decisiones que se tomen son falibles y de prueba porque no hemos enfrentado una situación similar.

Se generan conflictos relacionados con el biodesarrollo, como lo definen Maldonado \& Eschenhagen (2014, p.78) desarrollo en función de la vida en toda sus plenitud y complejidad. Una cuarentena mundial ha obligado al mundo a desacelerarse, con todo lo que ello implica.

\section{Materiales y métodos}

En la investigación se dieron lecturas a libros de las ciencias de la complejidad como Carlos Eduardo Maldonado, Edgar Morin y Codina Sotolongo, permitiendo escribir un dialogo con los autores.

\section{Resultados}

\section{La función del gobierno}

El papel del Gobierno en tiempos de pandemia ha tomado protagonismo, marcando lineamientos y estrategias a seguir, que las personas han legitimado a través de la obediencia y respeto a lo establecido, manteniéndose así la paz y el orden (relativamente). Se presenta una imagen de biopolítica, es decir que se orientan las decisiones a priorizar la vida en la mayoría de países (aunque no en todos). Lo coercitivo del gobierno se percibe con mucha más fuerza, se suprimen incluso derechos constitucionales temporalmente, como por ejemplo la libre locomoción a través de medidas como el toque de queda.

Existe mucho más control de las personas, todo con la finalidad de prepararse para un futuro incierto, sin embargo, esto produce suspicacias entre los habitantes debido a la excesiva invasión a la privacidad, por ejemplo, en países asiáticos los gobiernos tienen acceso a la ubicación, desplazamientos, e incluso con cierta tecnología pueden saber hasta la temperatura corporal de las personas, para determinar si están enfermas o no; ese tipo de información, a largo plazo, eso puede llegar a ser peligroso, sobre todo si llega a manos de diferentes entidades fuera del gobierno. 
Existe mucho temor de parte de la población, no sólo de contraer la enfermedad sino de lo que eso puede significar, como no poder ver más a su familia o en caso de fallecer tener que ser llevado a una fosa común, ya que se dice que no se da opción a las familias de velar y enterrar a sus parientes, sino es el gobierno quien se hace cargo de este tipo de acciones.

El sistema de salud como entidad principal, enfrenta muchos desafíos en países con recursos económicos, y aún más en países con pocos recursos como Guatemala; en primer lugar: la falta de camas, equipo, médicos, enfermeras, medicinas, etc., en un número de hospitales que también es insuficiente para cubrir las demandas de la población. En la mayoría de países se han hecho esfuerzos por preparar hospitales con lo necesario para atender esta emergencia, pese a ello, están las condicionantes que impone un virus altamente contagioso, que por sus características puede llegar a enfermar a un porcentaje tan alto de la población que los pocos centros asistenciales con que se cuenta corren el riesgo de colapsar y no ser capaces de atender a toda la población infectada.

En este sentido, las medidas restrictivas adoptadas por la mayoría de Estados en el mundo responden a evitar el contagio de la enfermedad al mayor número de habitantes, no sólo por el hecho del riesgo que representa dicho virus para grupos vulnerables de la población (personas con condiciones de enfermedades preexistentes y de edades avanzadas), sino por el riesgo de no contar con los recursos suficientes para atender médicamente a todas las personas y puedan morir por falta de atención, como sucedió en otros países. Estas medidas apuntan a priorizar la vida humana sobre todo lo demás, sin embargo, la salud, no es el único factor de vida que afecta a los seres humanos, está también el tema económico, que para las personas con ingresos altos o medios no es de vida o muerte, pero para las personas en condiciones de pobreza o pobreza extrema puede llegar a serlo.

Para cumplir su papel tutelar del bienestar general de la población, el gobierno de Guatemala específicamente ha estado llevando a cabo varias acciones, como por ejemplo entregar bonos económicos a los más necesitados, repartición de víveres, mascarillas y demás, así como incremento en los subsidios de servicios básicos como la energía eléctrica. Aunado a lo anterior, se tienen programas de préstamos para pequeños y medianos empresarios. Sin embargo, dichos programas no son capaces de llegar a toda la población en pobreza y muchas veces derivado de la falta de valores éticos, tampoco son repartidos justamente, y entonces se escucha la queja de las personas de las comunidades que argumentan que los Cocodes han entregado los víveres beneficiando a sus familiares y no realmente a las familias más pobres. Considerando que la mayoría de las familias son realmente pobres, es difícil determinar quien sí y quien no recibirá los beneficios.

Las medidas del gobierno deben considerar en todo momento dos puntos claves que son: evitar las muertes por la propagación del virus y sortear la crisis humanitaria originada de las condiciones que impone la cuarentena a los más pobres. No pueden tomarse posiciones extremas porque mientras las medidas más estrictas evitan la propagación del virus, a su vez, condicionan a las personas más pobres a morir de hambre, cobra vida aquí lo que dice Edgar Morín: "El arte de la política comporta inevitablemente una apuesta y, por lo tanto, el riesgo de equivocarse" (2011, p.19). 
Cabe agregar que la capacidad del gobierno para ayuda social es bastante limitada comparada con los índices de pobreza y exclusión que se viven en el país, considerando que las proyecciones por recaudación de impuestos no son favorecedoras y si se le suma la inversión extra que implica responder al fenómeno de la pandemia en Guatemala se ha incrementado considerablemente el endeudamiento, existiendo situaciones similares en el resto de países pobres de Latinoamérica. Por último, es importante destacar la función de liderazgo que deben ejercer los funcionarios públicos en virtud de generar tranquilidad y estabilidad a una población convulsa, llena de carencias y miedo en su mayoría, para evitar la ingobernabilidad y desestabilización del Estado como tal; considerando las experiencias de otros países en donde grupos de personas han salido a delinquir a las calles aduciendo condiciones de necesidad extrema.

\section{Consecuencias y retos para la economía}

En virtud que el biodesarrollo constituye según Maldonado \& Eschenbagen "un llamado a, y un ejercicio de construcción y fortalecimiento de la equidad" (2014, p.87), es innegable como el fenómeno del Covid-19 viene a tocar fibras importantes en este aspecto, considerando que actualmente los niveles de inequidad son muy elevados y esta pandemia amenaza con hacerlos aún más grandes.

Cuando se vislumbra la realidad de un porcentaje elevado de la población que ha perdido la capacidad de generar ingresos por las medidas adoptadas en esta pandemia, se suele justificar el fenómeno a través del precepto de que se "prioriza la vida humana", sin embargo, mientras más pobreza y vulnerabilidad enfrenta una población, más crítica y de vida o muerte puede considerarse también su economía.

Para una persona con recursos medios, no tiene tanto efecto la cuarentena como para una persona que vive del día a día. Quien come de lo que trabaja diario, está expuesto y vulnerable ante estos acontecimientos, no tiene una base o soporte para casos de contingencia, las palabras "Quédate en casa" pueden ser angustiantes y dolorosas. Para los países más pobres una paralización de la economía de esta envergadura significa una brecha aún mayor a superar con relación a los países más desarrollados. ¿Qué va a pasar cuando el dinero se termine para los grupos antes mencionados? ¿Será suficiente la ayuda social del gobierno? ¿Cómo van a reaccionar las masas con hambre y carencias? Todos los cuestionamientos anteriores hacen un llamado a la necesidad de trabajar por la equidad, en virtud que una sociedad en donde el mayor porcentaje de sus habitantes no satisfacen sus necesidades esenciales, corre mucho riesgo de colapsar.

La situación del sector empresarial en Guatemala es otro tema bastante complejo y delicado, siendo que las medidas que se adopten no sólo afectan a los empresarios y trabajadores sino a la economía de la población en general. Un punto que es importante aclarar es que existe un pequeño sector empresarial que ha sido beneficiado con este fenómeno, y aquí podemos mencionar como ejemplo a las farmacéuticas y los expendios de artículos de primera necesidad y abarrotes, sin embargo, existen empresas muy afectadas. 
Entre las estrategias que plantean los economistas para afrontar la crisis a las empresas con dificultades, está la reducción de sus costos al máximo para evitar la quiebra sobre todo de las más pequeñas o vulnerables por diversos motivos (niveles de endeudamiento, etc.). Esta reducción de costos, se evidencia humanamente en el despido de personal, que quedan desprovistos de ingresos en una época muy difícil. Sin embargo, forzar a las empresas a conservar todo su personal es en algunos casos una sentencia a la quiebra de las mismas y en consecuencia a largo plazo un número mayor de personas desempleadas.

Surge entonces el dilema, ¿Qué es preferible? Asegurar un ingreso a todos los trabajadores por tres o cuatro meses hasta que las empresas colapsen y cierren o permitir despidos temporales y parciales, con miras a mantener un porcentaje de empleos garantizados a largo plazo. Ahora bien, existen también los riesgos derivados del abuso y explotación de las empresas hacia sus trabajadores en virtud de las condiciones imperantes, existiendo patronos que teniendo las condiciones económicas aprovechan la situación para no cumplir con los pagos y prestaciones a sus trabajadores. El modelo de consumo que sostenía la economía ha cambiado, y no se sabe a ciencia cierta que puede pasar con cierto tipo de modelo de negocios, es probable que algunas costumbres cambien y eso conlleve también a patrones de consumo distintos. Se reduce el consumo derivado de la falta de recursos, lo que conlleva la recesión económica por la cuarentena. Gran porcentaje de la población no está percibiendo ingresos, por motivos tan diversos como el desempleo ocasionado por los cierres de empresas de muchos sectores y también los emprendedores que necesitan de contacto directo para ofrecer sus productos o servicios.

Se necesitan cambios estructurales en la sociedad que permitan salir de esta crisis como una sociedad unida, no a través de lo coercitivo o impositivo sino de valores sociales como la empatía, el trabajo, la solidaridad, vista esta última, no sólo hacia los semejantes, sino con el planeta en general. Es importante también reconocer que el sector empresarial, debe estar preparado para reaccionar en tiempos de cambio y reorientar sus estrategias. Si se quiere salir adelante como país es necesario cruzar las fronteras de la tecnología y reestructurar los modelos de negocios hacia lo emergente, pero sin olvidar la parte humana.

\section{Consecuencias y oportunidades para el medio ambiente:}

Cuando se habla de biodesarrollo surge entre otros temas: la conservación de la vida en el planeta (Maldonado \& Eschenbagen, 2014, p.87), es innegable que la forma en que los humanos hemos estado explotando el planeta, sin velar por la conservación de la vida, ha ocasionado estragos; se han perdido numerosas especies, está en riesgo la diversidad de la flora y fauna en muchos lugares, y el cambio climático camina hacia un punto sin retorno. El fenómeno del Coronavirus, ha repercutido en el tema del medio ambiente, no sólo a través de pequeños incentivos a la tierra, sino que, nos ha llamado a recapacitar sobre las posibilidades que aún tenemos. Varios medios informativos comparten evidencia que el principal beneficiado por el coronavirus en algunos países desarrollados ha sido el medio ambiente. En la página de National Geografic de España (2020), se pueden ver ejemplos de cómo las ciudades al paso de la cuarentena van presentando menores niveles de contaminación, derivado del cierre de fábricas, reducido tránsito de vehículos y poca afluencia de personas en las calles. Ha mejorado la calidad del aire y del agua y los lugares turísticos principales poco a poco lucen más limpios y despejados de basura y contaminación. 
A pesar de que algunos expertos opinan que estos cambios probablemente sean temporales, (se mantengan únicamente durante el período de la cuarentena), lo realmente importa es la actitud que tomarán los seres humanos ante ello. En los países más pobres, los problemas ambientales no giran tanto en torno a la contaminación ambiental derivada de la industria o el turismo, sino de la propia tradición y prácticas culturales consuetudinarias. Como ejemplo pueden mencionarse las quemas que realizan los campesinos para realizar sus siembras, que constituyen uno de los factores de riesgo para los incendios forestales en Guatemala, en donde se ha perdido gran parte de la cobertura forestal. La cuarentena no ha disminuido esta práctica en lo absoluto, se puede percibir el incremento en la temperatura y el aire contaminado por este tipo de prácticas.

La relación del hombre con la naturaleza debe empezar a visualizarse desde otras perspectivas más que las convencionales, debemos comprender que somos parte de la naturaleza y regresar a ella. El humano necesita estar en armonía con su entorno para encontrar la paz interior que trae la felicidad. Es preciso reflexionar sobre los patrones de conducta normalizados que son destructivos hacia el medio ambiente y replantear la vida. Un ejemplo de ello son los niveles consumo a nivel mundial, que no son coherentes a las necesidades reales, con miras a fomentar el biodesarrollo, entendido éste como procurador de vida.

\section{Coronavirus y educación}

Existe una crisis educativa mundial, y esa no es derivada del coronavirus, pero en este tiempo se hace más evidente. Se necesita educar para la vida, el ser humano debe aprender que existe un bien preciado innegociable que es la vida, y no sólo la de los seres humanos sino la del planeta como sistema vivo. Esta educación, no es la que se da a través de los sistemas formales, sino la que se vive en los hogares a través de las prácticas diarias. Como seres sociales construimos nuestro contexto a través de las prácticas rutinarias diarias realizadas consciente o inconscientemente (Sotolongo \& Delgado las clasifica en: tácita-pre reflexiva, inconsciente y consciente-reflexiva (2006, p.156)) dependiendo de nuestra posición de poder, deseo, saber o discurso y todo ello determina el tipo de sociedad en la que estamos establecidos.

Una educación que privilegie la vida, es aquella que enseña a respetar los ciclos de los sistemas vivos, a valorar y apreciar a los otros seres y a entender que no podemos pensar únicamente en nuestro propio bienestar sino en el del planeta que habitamos. Este tipo de educación, es urgente sobre todo en situaciones como la que vive el mundo actualmente, en donde se necesita una gran dosis de solidaridad, empatía y amor hacia los demás. Por otra parte, los sistemas educativos formales también influyen en los cambios sociales, y sobre todo coadyuvan a reducir las brechas entre ricos y pobres. A nivel mundial han sufrido grandes cambios, se ha imposibilitado la educación presencial, dando lugar a sustituir en los casos en que es factible este tipo de formación por la virtual. Los países más "desarrollados” y con recursos, no han sentido mucho el peso de la virtualidad derivado de que cuentan con las condiciones necesarias para continuar con este tipo de prácticas, pero, en los países más pobres, la educación para la mayoría de habitantes ha sido suspendida. No se cuenta con la estructura necesaria, no todos tienen acceso a internet, a computadoras, teléfonos inteligentes y luz eléctrica; condiciones necesarias para acceder. 
El sistema educativo en este momento en el país está colapsado, porque, aunque algunos sectores, continúen haciendo esfuerzos por educar desde la virtualidad, la mayoría de personas en Guatemala no cuenta con los recursos económicos ni tecnológicos para asumir el cambio a formación en línea. Incluso muchos de los maestros no cuentan con el conocimiento necesario para desarrollar este tipo de procesos. En estos tiempos la educación está siendo un lujo que sólo tiene cierto sector pudiente. Esto marcará mucho más los índices de exclusión social y la brecha económica entre ricos y pobres. A pesar de lo anterior es curioso que existan personas que tienden a negar los hechos y hacer referencia que en estos tiempos "todos tenemos acceso a teléfonos inteligentes e internet", que "quien no estudia es porque no quiere", cubriendo con el velo de sus palabras su conciencia oscura que se niega a ver la realidad fuera de sus cuatro paredes.

\section{Discusión}

Las palabras de Edgar Morín quien dice: "La solidaridad anónima de! estado de bienestar, que ofrece seguridades y garantías de todo tipo, es insuficiente. Hace falta una solidaridad concreta y vivida, de persona a persona, y entre grupos y personas" (2011, p.60), deben conducir a la reflexión que se necesita una nueva conciencia planetaria (Morín, 1995, p.1), que nos permita visualizarnos como sujetos activos, responsables, coparticipes de lo que sucede a nuestro alrededor, conscientes de que ningún hecho es aislado, ni pasa por casualidad.

No existen soluciones únicas para superar esta pandemia, no hay recetas mágicas ni dosis milagrosas, lo único que puede hacernos resurgir como sociedad es el camino hacia la equidad, hacia el respeto y hacia el todo. Siendo conscientes que la felicidad se consigue en la simbiosis del ser humano con su entorno, con su ambiente con sus semejantes, en un respeto que garantice la vida conjunta, armoniosa, equitativa para todos. Falta esperar si existe una voluntad que nos guíe hacia los cambios que tanto se necesitan como sociedad o somos secretamente conducidos hacia esta economía salvaje de autodestrucción para beneficiar intereses reducidos y particulares.

La vida y la espiritualidad tendrán una parte importante en estos cambios, visualizarnos como más que consumidores o productores y concebirnos como seres capaces de ser y hacer felices a los demás. Generar conciencia planetaria, implica comprender que como parte de un sistema nuestras acciones generan consecuencias que van más allá de lo que percibimos. Estamos en un proceso de redescubrimiento del mundo y sus características en el que ya no pretendemos reducirlo para entenderlo sino comprenderlo y explicarlo dentro de toda su complejidad sabiendo que siempre quedarán elementos sin considerarse, pero dejando abierto el espacio para continuar la construcción del conocimiento desde esta perspectiva.

Es un hecho que los sistemas económicos actuales no son capaces de satisfacer las necesidades de todas las personas de la sociedad en la que son aplicados, y esto derivado de que la razón por la que fueron creados, aunque en primera instancia fuese el bien común, ha sido desvirtuada a servir a beneficios particulares. Se venden expectativas mutuas que generan interacciones sociales que propician la acumulación de riqueza por las clases dominantes. La imprevisibilidad de la vida es más perceptible 
a la luz de los últimos acontecimientos mundiales, lo que hoy es, probablemente mañana ya no sea, la incertidumbre es la reina de todas las épocas (aunque no lo queramos ver), en que poco o nada sabemos de cómo transcurrirán los días, sin embargo, la vida nos invita a seguir viviendo con la misma intensidad y pasión, porque: "esto también pasará", depende de cada uno de nosotros, en qué se transforme el mundo.

\section{Referencias}

Maldonado, C. E. (2001). Visiones sobre la Complejidad Volúmen 1. Kimpres.

Maldonado, C. E. (2013). Significado e impacto social de las ciencias de la complejidad. Bogotá: Ediciones desde abajo.

Maldonado, C., \& Eschenhagen, M. (2014). Un viaje por las alternativas al desarrollo: Perspectivas y propuestas teóricas. Bogotá: Universidad Del Rosario.

Morín, E. (1995). Civilizar: La Nueva Conciencia Planetaria.

Morín, E. (2011). La vía para el futuro de la humanidad (Primera edición ed.). España: Paidos.

National Geografic. (2020). Recuperado el 10 de 04 de 2020, de https:/www.nationalgeographic.com.es/ ciencia/planeta-principal-beneficiado-por-coronavirus_15325

Sotolongo Codina, P., \& Delgado Díaz, C. (2006). La revoluciön contemporanea del saber y la complejidad social. Buenos Aires: Consejo Latinoamericano de Ciencias Sociales CLACSO.

\section{Sobre la autora}

\section{Nancy Carolina Castillo López}

Catedrática del Centro Universitario de Oriente de la Universidad de San Carlos de Guatemala, actualmente es Profesora Titular II e imparte los cursos de Introducción a la Economía, Administración Pública, Elaboración de Proyectos y Matemática en carreras de licenciatura y el curso de Didáctica en la Maestría en Docencia Universitaria. Además, es la Coordinadora del Programa de Formación Docente

Copyright (c) Nancy Carolina Castillo López

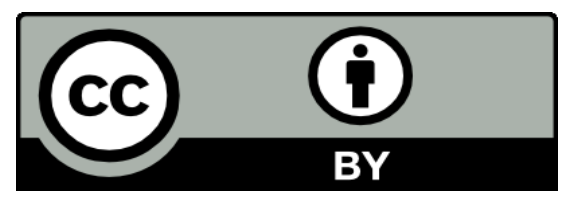

Este texto está protegido por una licencia CreativeCommons 4.0.

Usted es libre para compartir, copiar y redistribuir el material en cualquier medio o formato y adaptar el documento, remezclar, transformar y crear a partir del material para cualquier propósito, incluso comercialmente, siempre que cumpla la condición de atribución: usted debe reconocer el crédito de una obra de manera adecuada, proporcionar un enlace a la licencia, e indicar si se han realizado cambios. Puede hacerlo en cualquier forma razonable, pero no de forma tal que sugiera que tiene el apoyo del licenciante o lo recibe por el uso que hace. 